\title{
Chernobyl accident is blamed on human error
}

THe Chernobyl disaster was due to human factors or, in the words of the official dispatch, "a whole series of crude violations of the regulations for the operation of reactor installations". Such was the decision of a special session of the Politburo last weekend, after considering the report of the governmental commission that has been working at Chernobyl since the accident on 26 April. The full text of the report is expected to be published in midAugust.

According to the Politburo statement, during the night of 25/26 April, unauthorized investigations into the operating conditions of the turbogenerators were carried out on the Number 4 set, while it was out of service for a planned overhaul. Just what form these "experiments" took is unclear. The dispatch merely stated that the management and specialists of the power station had neither prepared themselves for the experiments nor coordinated them with the appropriate authorities, although they were legally bound to do so. Furthermore, there was no proper supervision of the experiments, nor were proper safety measures enforced while they were in progress. Several high officials have been dismissed for allowing this situation of "irresponsibility, negligence and lack of discipline" to develop.

By putting the blame squarely on the Chernobyl crew, the report would seem to exonerate the Soviet nuclear power programme and, in particular, the design of the RBMK reactor. But the unauthorized, unsupervised "experiments" could possibly have a more ominous explanation. In mid-May, some three weeks after the accident, there were some veiled references in the Soviet media to "experiments" at Chernobyl, followed by unattributed and unofficial reports that a malfunction on the Number 4 reactor had developed on the afternoon of 25 April, and that an emergency crew was still struggling to close it down when the explosion occurred. In this case, the "experiments" would refer to unauthorized or incorrect shutdown procedures, possibly undertaken as a last resort. In all events, the Politburo statement still fails to explain how an experiment with the turbogenerator could cause an explosion in the reactor.

Although the report was, presumably, completed only shortly before the Politburo meeting, the Soviet Procurator's Office has already instituted criminal proceedings against "the persons guilty of the accident at Chernobyl". In view of $\mathrm{Mr}$ Gorbachev's current drive for "open- ness", the trial is likely to be accorded maximum publicity. The Politburo statement outlines the charges against the accused: 28 people dead, damage to the health of a large number of people, including 203 cases of radiation sickness so far, the cost of large-scale prophylactic work (including medical checks on several hundred thousand people), $1,000 \mathrm{~km}^{2}$ of agricultural land taken out of production, the closure of various enterprises, the cost of evacuation and the rehousing of the evacuees, the loss of power production. The direct losses due to the accident are estimated at 2,000 thousand million roubles.

For the moment, the Politburo seems more concerned to ensure that such negligence will not occur again. Four senior officials have been dismissed: Evgenii Kulov, chairman of the state committee for safety in the nuclear power industry, G.A. Shasharin, a deputy minister of power and electrification, Aleksandr Meshkov, a first deputy minister of medium engineering, and Ivan Emelyanov, a deputy director of a research and development institute. In addition, all have been subjected to "rigorous Party penalties", as has also Bryukhanov, the former director of the Chernobyl power station who was dismissed in May.

The Minister for Power and Electrification, Anatolii Mayorets, was allowed to retain his post, but suffered a Party reprimand, and the public humiliation of being told that the Politburo had taken into account that he had only recently been appointed to the job, and that, "if he did not draw the appropriate conclusions", he would suffer a more severe penalty.

A new All-Union Ministry of Nuclear Energy has been established, in order to "raise the level of management and responsibility" in the nuclear power industry, and plans are under way for the retraining and requalification of nuclear power personnel. The use of simulators in training programmes is to be expanded, presumably to familiarize personnel with emergency procedures.

Furthermore, although the RBMK reactor design appears to have been officially exonerated, the Politburo has issued an urgent "demand" to all ministries and departments that they should draw up and implement additional measures to ensure the safety of existing reactors - and an appeal to scientists of the world to cooperate in developing a new generation of fission and, in the longer term, fusion reactors.
US and Pakistan

\section{Agreement on technology}

Washington

THE United States and Pakistan have signed an agreement to establish a framework for trade in high technology goods. The agreement will make it easier for Pakistan to obtain mainframe computers and modern telecommunications equipment but will also provide specific assurance that Pakistan will neither divert the goods to other countries, nor use them in ways not approved by the United States.

Pakistan Foreign Minister Yaqub Khan and US Secretary of State George Shultz signed the agreement at the White House last week during the visit of Prime Minister Mohammad Khan Junejo. Last year the United States signed a similar memorandum of understanding with India during Mr Rajiv Gandhi's trip to Washington. The Indian agreement has far greater economic significance than that being worked out with Pakistan. Trade with India amounts to approximately $\$ 1.600$ million per year, according to Commerce Department figures, and something like $\$ 75$ million of that is in high technology equipment, including computers.

By contrast, trade with Pakistan amounts to only $\$ 350-400$ million per year, with most of that consisting of aircraft, soya bean oil and heavy industrial equipment. According to a Commerce Department official, Pakistan is just beginning to automate its government, and with no domestic computer industry it will have to import everything it needs.

But the real significance of the Pakistan agreement may be political. Ken Flamm. a research associate at the Brookings Institution in Washington, says that the trade agreement will smoothe the Pakistani feathers, ruffled by the lack of an arrangement such as that already offered to India. At the same time it will give the United States some control over the way in which the high technology equipment is used.

The United States is primarily worried that Pakistan might use computers obtained under the agreement to further a nuclear weapons programme. While the United States does not believe that Pakistan now possesses nuclear weapons, it takes the view that Pakistan could produce such weapons in a fairly short space of time. Prime Minister June jo took some pains during his visit to emphasize the peaceful nature of Pakistan's nuclear programme. A joint statement issued by the two governments affirmed the Prime Minister's support of "US efforts to promote arms control and the non-proliferation of nuclear weapons". Joseph Palca 